\title{
Concerns about dental aesthetics are associated with oral health related quality of life in Southern Brazilian adults
}

\author{
Preocupações sobre a estética dentária com qualidade de vida \\ relacionada à saúde bucal em adultos no sul do Brasil
}

Mariél de Aquino Goulart ${ }^{1}$

Aline Macarevich Condessa ${ }^{1}$

Juliana Balbinot Hilgert ${ }^{1}$

Fernando Neves Hugo ${ }^{1}$

Roger Keller Celeste ${ }^{1}$

${ }^{1}$ Faculdade de Odontologia, Universidade Federal do Rio Grande do Sul. R. Ramiro Barcelos 2492/3o, Rio Branco. 90035-003 Porto Alegre RS Brasil. marielgoulart@gmail.com
Abstract It aims to evaluate the association between dental appearance and Oral Health Related Quality of Life. Fifteen primary care services with dental services were selected in Porto Alegre, Brazil. Individuals were interviewed from a random sampling of households in the catchment area of the health centres. The outcome was having an OHIP14 score $>0$ (any impact). The main exposures included self-reported tooth colour and position, perception of oral health and concern with dental aesthetics. Data were analysed with stepwise logistic regression. Of 1943 individuals contacted, 433 used public dental services in the last year. Seventy-three percent had some impact on quality of life, $35.2 \%$ and $47.5 \%$ reported stained and crowded teeth, respectively. Also, 22.2\% had already tried bleaching their teeth. Individuals concerned with colour were 2.56 times (95\% CI: 1.34-4.89) more likely to report any impact after adjusting for number of teeth, smoking and education. Concerns about tooth position, reporting stained or crowded teeth, age, sex and income were not significant $(p>0.30)$. There is a direct and independent association between concerns with tooth colour and quality of life. The effect of tooth colour on quality of life may be mediated by individuals' perceptions of aesthetics.

Key words Quality of life, Dental aesthetic malocclusion, Smoking, Tooth discoloration
Resumo O objetivo do presente estudo foi avaliar a associação entre a aparência dos dentes com a qualidade de vida relacionada à saúde bucal. Quinze centros de atenção primária com serviços odontológicos foram selecionados em Porto Alegre, Brasil. Os indivíduos foram entrevistados a partir de uma amostragem aleatória de domicílios. O desfecho avaliado foi ter um escore de OHIP14 $>$ 0. As exposições foram: cor e posição autorreferida dos dentes, percepção da saúde bucal $e$ preocupação com a estética dental. Os dados foram analisados com regressão logística. De 1.943 indivíduos contatados, 433 utilizaram os serviços públicos odontológicos, dos quais 73\% tinham algum impacto na qualidade de vida; $35,2 \%$ dentes manchados e 47,5\% dentes apinhados. Além disso, 22,2\% já haviam tentado clarear os dentes. Indivíduos preocupados com a cor tinham 2,56 vezes (IC 95\%: 1.34-4.89) mais chances de relatar qualquer impacto após o ajuste para número de dentes, tabagismo e educação. Preocupações com a posição dos dentes, relato de dentes manchados ou apinhados, idade, sexo e renda não foram significativas $(p>0,30)$. Houve uma associação direta e independente entre as preocupações com a cor do dente e qualidade de vida. O efeito da cor do dente pode ser mediado pela percepção da estética.

Palavras-chave Qualidade de vida, Estética Dentária, Má Oclusão, Hábito de Fumar, Descoloração de Dente 


\section{Introduction}

The public demand for aesthetic dentistry has been growing since the 90's and it stands as a relevant part of dentist's work nowadays. It has been reported that tooth colour is significantly related to satisfaction with dental appearance ${ }^{1}$. While position and colour play important role in dental aesthetic, the tooth colour may be more important than tooth position ${ }^{2,3}$. The most desired treatment to improve teeth appearance has been tooth whitening ${ }^{1,3,4}$, although there are differences among populations about perception of dental appearance $^{5}$ and about its importance.

Factors that can impact on tooth colouration include dental fluorosis, ageing, smoking, and dietary intake of coloured food ${ }^{6,7}$. Individuals with more darkened/yellowed teeth are considered less attractive when compared with those with whiter teeth ${ }^{8}$. Previous studies reported that about $66 \%$ of the population were not satisfied with their teeth colour ${ }^{1}$ and this increased with the severity of discoloration ${ }^{3,6}$. Regarding tooth position, quality of live has been shown to improve after orthodontic treatment ${ }^{9,10}$. In addition, orthodontic treatment improves aesthetic perception ${ }^{11}$ and this is independently associated with quality of life ${ }^{9}$.

So far, the mechanisms by which dental appearance is related to quality of life are not well described. It is possible that crowded and darkened teeth make people concerned about their health $^{6}$, affecting psychological wellbeing. To our knowledge, no study has tested the joint effect of tooth position and colour with concerns about health on quality of life. Therefore, the aims of this study were to evaluate the association between dental appearance and concerns about tooth colour and position and Quality of Life Related to Oral Health among adults.

\section{Materials and Methods}

This work is based on a cross-sectional population-based study, in which the primary objective was to evaluate differences in attributes of primary health care among three arrangements of public primary health care services provided in the city of Porto Alegre, Southern Brazil. The sample comprised residents in areas covered by fifteen primary health care centres that had one dentist, a dental assistant and/or a dental hygienist working for at least two years. A minimum of thirty individuals were interviewed in each pri- mary health care catchment area. A census track from the catchment area was randomly chosen. Then, one random street corner was chosen from simple randomization as starting point. All households in a block were visited until the minimum sample size was achieved according to the inclusion criteria. The inclusion criteria for the users were: having eighteen years of age or more; having used one of the health care centres in the twenty-four months prior to the study for dental examination or treatment; and being a permanent resident of the catchment area. If more than one adult fitted the inclusion criteria in a selected household, only one was chosen randomly. Selected users were interviewed by a trained field researcher using a structured questionnaire with closed questions.

The project was approved by the Ethics Committees in Research, under the numbers 10-120 (Ethics Committee in Research of the Conceição Hospital Group) and by Research Committee of the Federal University of Rio Grande do Sul.

\section{Main exposures}

Tooth colour and stain perception were assessed by a questionnaire developed by the Indiana University ${ }^{12}$ and adapted to Brazilian Portuguese by Furtado et al. ${ }^{13}$. The participant was asked to answer the following question "My teeth are:" from "very white" to "very stained/discoloured" using a five-level Likert-type scale; then respondent answered "Are you concerned about that?" (yes/no). The same questions were applied to ask about tooth position and dental health".

\section{Outcome variable}

Oral Health Related to Quality of Life was evaluated by the Brazilian Portuguese version of OHIP-14 as one overall score $\mathrm{e}^{14,15}$ The score of each individual was dichotomized in no impact on OHRQoL (OHIP $=0$ ) or any impact when higher than zero (OHIP $\geq 1$ ).

\section{Covariates}

Socio-demographic and dental status variables were included as potential confounders. The number of teeth in the mouth was obtained by asking to respondents how many remaining teeth they had left in each jaw. In analysis, this variable was dichotomized as functional dentition ( $>20$ permanent teeth in mouth) or not ( $\leq$ 20 teeth). People were asked if they use to smoke, 
if they have never smoked or if they have stopped. Smoking variable was created by dichotomizing the answers in current smokers or not. The participant was also asked if he or she has ever tried to bleach his/her teeth. In the analysis we categorized this as has never bleached, tried to bleach at home (e.g. using whitening toothpaste) or tried to bleach with a dentist. Socio-demographic information were evaluated by questions that asked for date of birth, sex, income (categorized in minimum wages, equivalized by square root of the number of individuals at the household), and education (categorized in years of schooling, according to educational attainment).

\section{Analysis}

Descriptive analyses were presented by means and standard deviations for continuous variables and proportions for categorical variables. Bivariate analyses were performed between OHIP14 $>0$ and covariates testing their association with chi-square test. Multiple logistic regressions were undertaken to calculate crude and adjusted odds ratio with $95 \%$ confidence intervals $(95 \% \mathrm{CI})$. For the adjusted model, the backwards stepwise methods was used with a $\mathrm{p}>0.30$ for removal of variables. Model fit was assessed with Hosmer-Lemeshow Goodness-Of-Fit (GOF) test and with the proportion of cases correctly classified ${ }^{16}$.

Multiplicative interactions between concerns with tooth colour and concerns with tooth position were tested against the following variables: sex, age, number of teeth, education, income, tooth position, tooth colour, having previously bleached their teeth, and smoking.

Database was built by scanning the questionnaires with Teleform Software and data edition and analysis were performed using Stata 13.1.

\section{Results}

In this survey, 1943 individuals were contacted. Eighty-one refused to participate while 1429 were not eligible due to exclusion criteria (most of them were not treated by the dentist in the Primary Care Service). We completed 433 interviews (84\% of response rate among those eligible), but due to missing data in at least one of variables, 390 individuals were included in the final multiple regression model. Their age ranged from 18 to 86 years old.

Of the 433 participants, $310(73.3 \%)$ had some impact on quality of life. Most of partici- pants were females $(79.9 \% \mathrm{n}=338)$, the largest age group was $35-54$ years old $(38.5 \% n=163)$, and those with complete high school comprised $39.7 \%$ of the sample $(\mathrm{n}=168)$. Seventy-eight percent $(n=330)$ of the sample reported they never tried tooth bleaching while $33.6 \%$ ( $\mathrm{n}=$ 142) reported they were concerned about their tooth position. More than $50 \%$ of the sample described themselves as having white and/or healthy teeth (Table 1).

There was no statistical significance $(\mathrm{p}>0.05$, chi-square) between the prevalence of OHIP $>0$ and the following variables: gender, age, smoking, income, previous teeth bleaching, concerns with tooth position, and position or health of the teeth. However, $79.6 \%(\mathrm{n}=140)$ of individuals with 20 or less teeth had an OHIP14 $>0$ (p $<0.02$ ) compared to $69.4 \%$ of individuals with more than 20 teeth. Also, some individuals reported to be concerned with their teeth's colour $(48.4 \% \mathrm{n}=205)$ and/or health $(52.4 \% \mathrm{n}=222)$ and, around $80.0 \%$ of those had an impact on quality of life $(\mathrm{p}<0.01)$.

In the crude model, subjects with concern about their tooth position had an Odds Ratio (OR) of 1.55 (95\%CI 0.96-2.51), but this was not significantly associated with quality of life. However, concern with tooth colour and teeth health showed OR $=2.73(95 \% \mathrm{CI} 1.73-4.32)$ and $\mathrm{OR}=2.78$ (95\%CI 1.76-4.37), respectively. Multiple regression analysis was adjusted by functional dentition, smoking, educational level, concerns about health and colour of teeth. Those who reported to be concerned with colour and health of teeth presented, respectively, OR $=2.56(95 \% \mathrm{CI}$ $1.34-4.89)$ and $\mathrm{OR}=2.00(95 \% \mathrm{CI} 1.09-3.67)$ more chances to have an impact on quality of life than those not concerned. All the variables added to the adjusted model, except smoking, were statistically significant $(\mathrm{p}>0.05)$ (Table 2).

None of the interactions tested (see methods) showed statistical significance $(p>0.05)$; therefore they were not presented. The fit of the final model showed to be acceptable (GOF test, $p=$ 0.42 ) with $74.3 \%$ of cases correctly classified by the predictors.

\section{Discussion}

In this study, we found an association between self-reported tooth colour and tooth position with Oral Health Related to Quality of Life (OHRQoL) and also between concerns about colour and position with OHRQoL. However, 
Table 1. Prevalence of individuals reporting any impact in Oral Health Related Quality of Life (OHIP14) according sociodemographic and aesthetic factors among Brazilian public dental care users.

\begin{tabular}{|c|c|c|c|c|c|c|}
\hline & & \multicolumn{2}{|c|}{ Total Sample } & \multicolumn{2}{|c|}{ OHIP14 $>0$} & \multirow[t]{2}{*}{ p-value ${ }^{x}$} \\
\hline & & $\%$ & $\mathbf{N}$ & $\%$ & $\mathbf{n}$ & \\
\hline \multicolumn{2}{|l|}{ Total } & 100.0 & 423 & 73.3 & 310 & \\
\hline \multirow[t]{2}{*}{ Sex } & Male & 20.1 & 85 & 71.8 & 61 & 0.72 \\
\hline & Female & 79.9 & 338 & 73.7 & 249 & \\
\hline \multirow[t]{3}{*}{ Age Brackets $^{\star *}$ (years) } & $18-34$ & 22.9 & 97 & 72.2 & 70 & 0.35 \\
\hline & $35-54$ & 38.5 & 163 & 69.9 & 114 & \\
\hline & $>54$ & 36.4 & 154 & 76.6 & 118 & \\
\hline \multirow[t]{2}{*}{ Functional Dentition } & $>20$ teeth & 59.6 & 252 & 69.4 & 175 & 0.02 \\
\hline & 20 teeth or less & 41.6 & 176 & 79.6 & 140 & \\
\hline \multirow[t]{2}{*}{ Smoking } & Stopped/never & 75.4 & 319 & 74.6 & 238 & 0.39 \\
\hline & Current smoker & 25.5 & 108 & 70.4 & 76 & \\
\hline \multirow{4}{*}{$\begin{array}{l}\text { Education (year of } \\
\text { schooling** }\end{array}$} & $>11$ year & 8.3 & 35 & 54.3 & 19 & 0.11 \\
\hline & $9-11$ year & 30.5 & 129 & 77.5 & 100 & \\
\hline & 5-8 year & 39.7 & 168 & 72.0 & 121 & \\
\hline & $0-4$ years & 21.0 & 89 & 78.7 & 70 & \\
\hline \multirow{5}{*}{$\begin{array}{l}\text { Equivalent income in } \\
\text { Minimum wages }\end{array}$} & Up to $1 / 2 \mathrm{MW}$ & 9.5 & 40 & 67.5 & 27 & 0.12 \\
\hline & 1/2-1 MW & 23.4 & 99 & 69.7 & 69 & \\
\hline & $1-2 \mathrm{MW}$ & 40.4 & 171 & 74.9 & 128 & \\
\hline & 2-3 MW & 14.7 & 62 & 75.8 & 47 & \\
\hline & $>3 \mathrm{MW}$ & 13.2 & 56 & 78.6 & 44 & \\
\hline \multirow{3}{*}{$\begin{array}{l}\text { Have you tried bleaching your } \\
\text { teeth? }\end{array}$} & Never & 77.8 & 330 & 73.9 & 244 & 0.21 \\
\hline & Toothpaste/Home methods & 10.9 & 46 & 80.4 & 37 & \\
\hline & At the Dentist & 11.3 & 48 & 64.6 & 31 & \\
\hline \multirow[t]{2}{*}{ Concern with position } & No & 66.0 & 279 & 70.6 & 197 & 0.07 \\
\hline & Yes & 33.6 & 142 & 78.9 & 112 & \\
\hline \multirow[t]{2}{*}{ Concern with colour } & No & 50.6 & 214 & 64.0 & 137 & $<0.00$ \\
\hline & Yes & 48.5 & 205 & 82.9 & 170 & \\
\hline \multirow[t]{2}{*}{ Concern with dental health } & No & 45.2 & 191 & 62.8 & 120 & $<0.00$ \\
\hline & Yes & 52.5 & 222 & 82.4 & 183 & \\
\hline \multirow[t]{2}{*}{ Are your teeth crowded? } & Aligned teeth & 66.0 & 279 & 71.0 & 198 & 0.09 \\
\hline & Crowded teeth & 35.2 & 149 & 78.5 & 117 & \\
\hline \multirow[t]{2}{*}{ Are you teeth white? } & White teeth & 56.5 & 239 & 69.0 & 165 & 0.02 \\
\hline & Stained teeth & 44.7 & 189 & 79.4 & 150 & \\
\hline \multirow[t]{2}{*}{ Are you teeth healthy? } & Healthy teeth & 53.7 & 227 & 70.8 & 196 & 0.08 \\
\hline & Ill teeth & 35.2 & 149 & 78.5 & 117 & \\
\hline
\end{tabular}

* chi-square test for heterogeneity.

self-reported indicators lost their effect after controlling for concerns about colour and position. Secondly, we described a relatively high prevalence of aesthetic concerns about tooth position and colour.

Among limitations of the study we highlight three points. First, the impossibility to determine temporality due to study design; although it is implausible that, quality of life would influence tooth position/colour. Second, measurement error is an issue due to the subjectivity of self-re- ported tooth position and colour. However, we believe that self-reported aesthetic problems may be more relevant than normative indices regarding the identification of an individual's problem. Furthermore, it is uncommon to have clinical exams in household surveys. Finally, the present work deals with a specific population of users of public health services and prevalence data cannot be extrapolated to general population. Nevertheless, this is a population-based (household) sample, in which we managed to have adequate 
Table 2. Odds ratio (OR) of having any impact on quality of life (OHIP14>0) for different variables among primary health care users in south Brazil.

\begin{tabular}{|c|c|c|c|c|c|c|c|}
\hline \multicolumn{2}{|l|}{ Variable / Category } & \multirow{2}{*}{$\frac{\mathbf{O R}_{\text {crude }}}{1}$} & \multicolumn{2}{|c|}{$95 \% \mathrm{CI}$} & \multirow[t]{2}{*}{$\mathbf{O R}_{\text {adjusted }}^{\star}$} & \multicolumn{2}{|c|}{ 95\%CI } \\
\hline Sex & Male & & & & & & \\
\hline & Female & 1.10 & 0.65 & 1.87 & & & \\
\hline Age Brackets ${ }^{\star *}$ (years) & $18-34$ & 1 & & & & & \\
\hline & $35-54$ & 0.90 & 0.51 & 1.56 & & & \\
\hline & $>54$ & 1.26 & 0.71 & 2.26 & & & \\
\hline Functional Dentition & $>20$ teeth & 1 & & & 1 & & \\
\hline & 20 teeth or less & 1.71 & 1.09 & 2.69 & 1.84 & 1.07 & 3.16 \\
\hline Smoking & Stopped/never & 1 & & & 1 & & \\
\hline & Current smoker & 0.81 & 0.50 & 1.31 & 0.70 & 0.42 & 1.21 \\
\hline Education (year of & $>11$ years & 1 & & & 1 & & \\
\hline schooling $^{\star *}$ & 9-11 years & 2.90 & 1.33 & 6.35 & 3.44 & 1.43 & 8.24 \\
\hline & $5-8$ years & 2.17 & 1.03 & 4.57 & 2.62 & 1.12 & 6.10 \\
\hline & $0-4$ years & 3.10 & 1.34 & 7.16 & 3.16 & 1.20 & 8.27 \\
\hline Equivalent income in & Up to $1 / 2 \mathrm{MW}$ & 1 & & & & & \\
\hline Minimum wages ${ }^{\star *}$ & 1/2-1 MW & 1.11 & 0.50 & 2.44 & & & \\
\hline & 1-2 MW & 1.43 & 0.68 & 3.02 & & & \\
\hline & 2-3 MW & 1.51 & 0.63 & 3.64 & & & \\
\hline & $>3 \mathrm{MW}$ & 1.77 & 0.70 & 4.43 & & & \\
\hline Have you tried bleaching & Never & 1 & & & & & \\
\hline your teeth? & Using toothpaste/Home methods & 1.45 & 0.67 & 3.13 & & & \\
\hline & At the Dentist & 0.64 & 0.34 & 1.22 & & & \\
\hline Concern with position & No & 1 & & & 1 & & \\
\hline & Yes & 1.55 & 0.96 & 2.51 & 0.61 & 0.31 & 1.20 \\
\hline Concern with colour & No & 1 & & & 1 & & \\
\hline & Yes & 2.73 & 1.73 & 4.32 & 2.56 & 1.34 & 4.89 \\
\hline Concern with dental health & No & 1 & & & 1 & & \\
\hline & Yes & 2.78 & 1.76 & 4.37 & 2.00 & 1.09 & 3.67 \\
\hline Are your teeth crowded? & Aligned teeth & 1 & & & & & \\
\hline & Crowded teeth & 1.52 & 0.95 & 2.43 & & & \\
\hline Are you teeth white? & White teeth & 1 & & & & & \\
\hline & Stained teeth & 1.75 & 1.12 & 2.73 & & & \\
\hline Are you teeth healthy? & Healthy teeth & 1 & & & & & \\
\hline & Ill teeth & 1.51 & 0.95 & 2.42 & & & \\
\hline
\end{tabular}

* Stepwise Backwards $\mathrm{p}<0.30$.

confounders to test our hypothesis, including not only colour and alignment but also testing if their effect persisted after controlling for concerns. Due to the strategy of having a household survey, our sample avoided the bias of interviewing people at a clinical setting.

We reported a significant association between quality of life and concerns with dental aesthetics. A recent study regarding the association between concerns with tooth colour and quality of life also reported a significant association ${ }^{17}$. In such study, colour and position were considered the most influential variables to explain a quality of life score being developed. In addition, evidence suggests that mild fluorosis may be associated with better $\mathrm{OHRQOL}^{7}$ although another study showed that the diagnosis of mild fluorosis (white stained tooth) was not significantly correlated with satisfaction with appearance ${ }^{13}$.

In a review of dentofacial aesthetics and quality of life ${ }^{18}$, it was concluded that almost one-third of people might tend to overrate their own dental appearance while 1 in 7 might be over-concerned compared to a professional opinion. A study comparing before-and-after bleaching treatment reported that problems with smiling 
decreased from $9.8 \%$ to $3.3 \%{ }^{19}$. One explanation for the association between concern and quality of life could be that "concerned" individuals value highly their dental aesthetic, and this may impact in their quality of life because such people may change their social and psychological behaviour ${ }^{20}$. In this case, concerned individuals can reduce their social life due to shame or fear of discrimination as described in a previous study ${ }^{21}$.

In the crude model, tooth colour and alignment were associated with quality of life; however, in the adjusted model they lost significance. Perhaps, both variables are not directly associated with quality of life since their effect is mediated by individuals' expectations, impacting more than the health status itself ${ }^{22}$. Literature related to aesthetic factors tends to be more focused on teeth alignment and shows a significant association between aesthetic impact due to malocclusion with biopsychosocial variables ${ }^{23-25}$ as well as with quality of life ${ }^{9,26}$. Although the mediation hypothesis is plausible, loss of association of normative indicators in adjusted models could also be due to measurement error. A study has shown that normative criteria overestimate malocclusion problems when compared to self-perceived experience ${ }^{27}$ and there is high variability in the treatment need perception among specialists and layperson $\mathrm{s}^{28}$.

Dental appearance seems to be a general concern among users of Brazilian public health system as $48.5 \%$ of those interviewed reported to be concerned with tooth colour, $33.6 \%$ were concerned with tooth position and $22.2 \%$ already tried to bleaching (10.9\% at home and $11.3 \%$ at the dentist). The prevalence of tooth bleaching was lower in other countries; $9.1 \%$ and $27.0 \%$ respectively, in Turkey ${ }^{29}$ and Israel ${ }^{4}$. Importantly, there is no bleaching treatment available in the Brazilian Public Health System; therefore, those who tried bleaching at the dentist went to the private sector.

In the public sector, due to the restricted funding, it is necessary to list priorities.It could be argued that the public system should provide treatment and prevention to health conditions that may threat life, cause pain or disability and not the so-called cosmetic problems. Our results do not support that bleaching should be offered in the public health system to improve quality of life, as this association needs to be better understood before any further action. Although aesthetics is not a priority of SUS, professionals must provide comprehensive, patient-centred care, accepting and considering their demands. Aesthetics may be related to differences in employment opportunities and discrimination, becoming a concern also for underprivileged populations.

Our results suggest that colour may impact more than position. Accordingly, previous studies regarding dissatisfaction with dental appearance in Turkey ${ }^{29}$, Israel $^{4}$, Malaysia ${ }^{3}$ and Saudi Ara$b^{1} a^{1}$, reported a variation in dissatisfaction from $37.3 \%$ to $51.8 \%$. In those countries, respectively, $56.2 \%$ to $89.3 \%$ considered tooth colour as first reason for dissatisfaction and $23.7 \%$ to $41.8 \%$ considered poor tooth alignment.

There is a direct and independent association between concerns about dental aesthetics and oral health with quality of life, taking into account potential confounders. More studies are needed in other populations to verify this association in different contexts. This study shows that anxieties and concerns may affect quality of life, even admitting that aesthetic concerns may seem trivial. Finally, more attention should be paid to the individual's self-assessment of oral health and not only to the clinical indices measured by the professional. Differences exist between the impacts of self-perceived and normatively assessed dental esthetics on the OHRQoL, so it is important the self-assessment to evaluate the impact of aesthetic concern in quality of life ${ }^{30}$. It needs to be confirmed in future studies if concerns with colour and position are mediators of the relation between aesthetics and quality of life. 


\section{Collaborations}

RK Celeste, JB Hilgert and FN Hugo contributed to study design. MA Goulart contributed to data collection and RK Celeste to data analysis. MA Goulart and AM Condessa wrote a first draft. All authors interpreted the results, revised critically the manuscript and approval of the final version for publication.

\section{Acknowledgments}

The study was supported by two grants from the Fundação de Apoio a Pesquisa do Rio Grande do Sul (FAPERGS), Brazil. RKC and JBH hold a PQ-2 CNPq Fellowship.

\section{References}

1. Al-Zarea BK. Satisfaction with appearance and the desired treatment to improve aesthetics. Int J Dent 2013; 2013:912368.

2. Sulieman MA. An overview of tooth-bleaching techniques: chemistry, safety and efficacy. Periodontol 2000 2008; 48:148-169.

3. Tin-Oo MM, Saddki N, Hassan N. Factors influencing patient satisfaction with dental appearance and treatments they desire to improve aesthetics. BMC Oral Health 2011; 11(1):6.

4. Samorodnitzky-Naveh GR, Geiger SB, Levin L. Patients' satisfaction with dental esthetics. J Am Dent Assoc 2007; 138(6):805-808.

5. Vallittu PK, Vallittu AS, Lassila VP. Dental aesthetics a survey of attitudes in different groups of patients. $J$ Dent 1996; 24(5):335-338.

6. Alkhatib MN, Holt R, Bedi R. Prevalence of self-assessed tooth discolouration in the United Kingdom. J Dent 2004; 32(7):561-566.

7. Chankanka O, Levy SM, Warren JJ, Chalmers JM. A literature review of aesthetic perceptions of dental fluorosis and relationships with psychosocial aspects/oral health-related quality of life. Community Dent Oral Epidemiol 2010; 38(2):97-109.

8. Hendrie CA, Brewer G. Evidence to suggest that teeth act as human ornament displays signalling mate quality. PLoS One 2012; 7(7):e42178.

9. Feu D, Miguel JAM, Celeste RK, Oliveira BH. Effect of orthodontic treatment on oral health-related quality of life. Angle Orthod 2013; 83(5):892-898.

10. Palomares NB, Celeste RK, Oliveira BH, Miguel JAM. How does orthodontic treatment affect young adults' oral health-related quality of life? Am J Orthod Dentofac Orthop 2012; 141(6):751-758.

11. Feu D, Oliveira BH, Celeste RK, Miguel JAM. Influence of orthodontic treatment on adolescents' self-perceptions of esthetics. Am J Orthod Dentofac Orthop 2012; 141(6):743-750.

12. Martínez-Mier EA, Maupomé G, Soto-Rojas AE, et al. Development of a questionnaire to measure perceptions of, and concerns derived from, dental fluorosis. Community Dent Heal 2004; 21(4):299-305.

13. Furtado GE, Sousa ML, Barbosa TS, Wada RS, Martínez-Mier EA, Almeida ME. Perceptions of dental fluorosis and evaluation of agreement between parents and children: validation of a questionnaire. Cad Saude Publica 2012; 28(8):1493-1505.

14. Oliveira BH, Nadanovsky P. Psychometric properties of the Brazilian version of the Oral Health Impact Profile-short form. Community Dent Oral Epidemiol 2005; 33(4):307-314.

15. Santos CM dos, Oliveira BH de, Nadanovsky P, Hilgert JB, Celeste RK, Hugo FN. The Oral Health Impact Profile-14:: a unidimensional scale? Cad Saude Publica 2013; 29(4):749-757.

16. Hormer D, Lemeshow S. Applied Logist Regression. New York: Willey; 2000.

17. Daneshvar M, Devji TF, Davis AB, White MA. Oral health related quality of life: a novel metric targeted to young adults. J Public Health Dent 2015; 75(4):298-307.

18. Klages U, Zentner A. Dentofacial Aesthetics and Quality if Life. Semin Orthod 2007; 13(2):104-115. 
19. Meireles SS, Goettems ML, Dantas RVF, Bona A Della, Santos IS, Demarco FF. Changes in oral health related quality of life after dental bleaching in a double-blind randomized clinical trial. J Dent 2014; 42(2):114-121.

20. Afroz S, Rathi S, Rajput G, Rahman SA. Dental esthetics and its impacts on psycho-social well-being and dental self confidence: a campus based survey of north Indian university students. J Indian Prosthodont Soc 2013; 13(4):455-460.

21. Newton JT, Prabhu N, Robinson PG. The impact of dental appearance on the appraisal of personal characteristics. Int J Prosthodont 2003; 16(4):429-434.

22. Fleck MPA. [The Evaluation of Quality of Life: A Guide for Health Professionals] in Portuguese. Porto Alegre: Artmed; 2008.

23. Marques LS, Filogônio CA, Filogônio CB, Pereira LJ, Pordeus IA, Paiva SM, Ramos-Jorge ML. Aesthetic impact of malocclusion in the daily living of Brazilian adolescents. J Orthod 2009; 36(3):152-159.

24. Gazit-Rappaport T, Haisraeli-Shalish M, Gazit E. Psychosocial reward of orthodontic treatment in adult patients. Eur J Orthod 2010; 32(4):441-446.

25. Marques LS, Ramos-Jorge ML, Paiva SM, Pordeus IA. Malocclusion: esthetic impact and quality of life among Brazilian schoolchildren. Am J Orthod Dentofacial Orthop 2006; 129(3):424-427.

26. Feu D, Oliveira BH, Oliveira Almeida MA, Kiyak HA, Miguel JA. Oral health-related quality of life and orthodontic treatment seeking. Am J Orthod Dentofac Orthop. 2010; 138(2):152-159.
27. Peres KG, Traebert ES, Marcenes W. Differences between normative criteria and self-perception in the assessment of malocclusion. Rev Saude Publica 2002; 36(2):230-236.

28. Livas C, Delli K. Subjective and objective perception of orthodontic treatment need: A systematic review. Eur J Orthod 2013; 35(3):347-353.

29. Akarslan Z, Erten H, Karabulut E, Sadik B. Dental esthetic satisfaction, received and desired dental treatments for improvement of esthetics. Indian J Dent Res 2009; 20(2):195-200.

30. Isiekwe G, Sofola O, Onigbogi O, Utomi IL, Sanu OO, Costa OO. Dental esthetics and oral health-related quality of life in young adults. Am J Orthod Dentofacial Orthop 2016; 150(4):627-636.

Artigo apresentado em 02/09/2016

Aprovado em 25/11/2016

Versão final apresentada em 27/11/2016 